\title{
Central obesity, insulin resistance, syndrome X, lipoprotein(a), and cardiovascular risk in Indians, Malays, and Chinese in Singapore
}

\author{
Kenneth Hughes, Tar-Choon Aw, Ponnudurai Kuperan, Maurice Choo
}

\begin{abstract}
Study objective-To examine the hypothesis that the higher rates of coronary heart disease (CHD) in Indians (South Asians) compared with Malays and Chinese is at least partly explained by central obesity, insulin resistance, and syndrome $\mathbf{X}$ (including possible components).
\end{abstract}

Design-Cross sectional study of the general population.

Setting-Singapore.

Participants-Random sample of 961 men and women (Indians, Malays, and Chinese) aged 30 to 69 years.

Main results-Fasting serum insulin concentration was correlated directly and strongly with body mass index (BMI), waist-hip ratio (WHR), and abdominal diameter. The fasting insulin concentration was correlated inversely with HDL cholesterol and directly with the fasting triglyceride concentration, blood pressures, plasminogen activator inhibitor 1 (PAI-1), and tissue plasminogen activator (tPA), but it was not correlated with LDL cholesterol, apolipoproteins $B$ and A1, lipoprotein(a) $(\operatorname{Lp}(a))$, fibrinogen, factor VIIc, or prothrombin fragment $(F) 1+2$. This indicates that the former but not the latter are part of syndrome $X$. While Malays had the highest BMI, Indians had a higher WHR (men 0.93 and women 0.84) than Malays (men 0.91 and women 0.82 ) and Chinese (men 0.90 and women 0.82 ). In addition, Indians had higher fasting insulin values and more glucose intolerance than Malays and Chinese. Indians had lower HDL cholesterol, and higher PAI-1, tPA, and $\operatorname{Lp}(a)$, but not higher LDL cholesterol, fasting triglyceride, blood pressures, fibrinogen, factor VIIc, or prothrombin F1 + 2 .

Conclusions-Indians are more prone than Malays or Chinese to central obesity with insulin resistance and glucose intolerance and there are no apparent environmental reasons for this in Singapore. As a consequence, Indians develop some but not all of the features of syndrome $X$. They also have higher $\operatorname{Lp}(a)$ values. All this puts Indians at increased risk of atherosclerosis and thrombosis and must be at least part of the explanation for their higher rates of CHD.

( $\mathcal{A}$ Epidemiol Community Health 1997;51:394-399)
Indians or South Asians (ie, persons from the Indian subcontinent) have been found in a number of countries to be particularly susceptible to coronary heart disease (CHD). It has been shown, however, that this is not a result of the classic risk factors of cigarette smoking, hypertension, and increased low density lipoprotein (LDL) cholesterol. ${ }^{12}$

Insulin resistance, which leads to hyperinsulinaemia and is associated with centralised adiposity (preferential deposition of adipose tissue on the trunk and intra-abdominally), has been related to both diabetes and $\mathrm{CHD}^{3}$ and is a possible mechanism for high rates of both diseases in Indians. Syndrome X (Reaven's or insulin resistance syndrome) is characterised by increased insulin resistance, glucose intolerance, hypertension, and dyslipidaemia with high fasting triglyceride and low high density lipoprotein (HDL) cholesterol concentrations. ${ }^{4} \mathrm{~A}$ higher frequency of this syndrome related to central obesity has been reported in Indians. ${ }^{5}$ It has been found in Britain, both in London ${ }^{6}$ and to some extent, though not completely, in Bradford. ${ }^{7}$ However, these comparisons were with white people and differences in the components of the syndrome may not be the same when Indians are compared with other Asians.

Syndrome $\mathrm{X}$ is being expanded and has recently been called the "athero-thrombogenic syndrome" showing both atherosclerotic and thrombotic components. It can include increased plasminogen activator inhibitor type 1 (PAI-1) ${ }^{8}$ and possibly other haemostatic factors. There has been increasing interest in the role of haemostatic factors in the aetiology of CHD. ${ }^{9}$ Lipoprotein(a) (Lp(a)) has LDL-like properties that increase atherosclerosis. ${ }^{10}$ In addition, $\operatorname{Lp}(\mathrm{a})$, which is structurally similar to plasminogen, inhibits plasminogen binding to the endothelial cell, thus interfering with plasmin generation, and promotes endothelial cell synthesis of PAI-1, which inhibits tissue plasminogen activator (tPA) and hence reduces fibrinolysis. ${ }^{11} \mathrm{Lp}(\mathrm{a})$ is therefore both atherogenic and thrombogenic.

Singapore is an island state with a population of 3.3 million people composed of Chinese $76 \%$, Malays $14 \%$, Indians $7 \%$, and "others" $3 \%$ whose origins have been described. ${ }^{12}$ of the Indians, $80 \%$ originate from the southern states of India (Tamil Nadu and Kerala) and Sri Lanka. Singapore has undergone rapid economic development over the last three decades and the commonest causes of death are now cardiovascular diseases and cancers. Mortality 
rates from CHD are highest in Indians then Malays and then Chinese for both genders. ${ }^{12} \mathrm{~A}$ population based survey (the Singapore thyroid and heart study) found that, as elsewhere, Indians did not have higher cigarette smoking rates, blood pressures, or LDL cholesterol concentrations but did have more diabetes and lower HDL cholesterol values. ${ }^{13}$ The National University of Singapore heart study is a further population based survey of cardiovascular risk factors, including the newer ones not studied previously One of its objectives is to identify reasons for the increased susceptibility of Indians to CHD. This paper examines central obesity, insulin resistance, and syndrome $\mathrm{X}$ (including possible components).

\section{Methods \\ SAMPLE}

This cross sectional survey was of a random sample of persons aged 30 to 69 years from the general population of Singapore. The sample was obtained from two sources-the thyroid and heart study, ${ }^{13}$ and electoral registers of five divisions, each in a different part of the island (north, south, east, west, and centre). There was disproportionate sampling in relation to ethnic groups to obtain equal numbers of subjects in each of the six gender-ethnic groups. The required sample was 180 subjects in each gender-ethnic group giving a total of 1080 subjects. Assuming that $20 \%$ of the subjects would not be recruitable because of death, migration, infirmity, or relocation (which is high in Singapore due to massive urban redevelopment), and assuming a response rate of $75 \%$, a total of 1800 persons was selected. Of these, 419 (23.3\%) were not recruitable and 983 responded, giving a response rate of $71.2 \%$. Of the 983 subjects, 22 were 70 years or over and were excluded, leaving 961 persons aged between 30 and 69 years.

\section{PROCEDURES}

Morning clinics were held from June 1993 to December 1995, with both genders and three ethnic groups seen concurrently. Subjects were asked to fast from 21.00 hours the previous evening. Questionnaires were administered by a nurse trained in interview techniques with questions on age, gender, ethnic group (classification previously described, ${ }^{12}$ ) occupation, exercise, cigarette smoking, and alcohol consumption.

Anthropometric measurements were carried out by a nurse trained in the techniques. Height (to the nearest $0.1 \mathrm{~cm}$ ) and weight (to the nearest $0.1 \mathrm{~kg}$ ) were measured on a SECA machine without shoes and in light clothing after emptying all pockets. Waist circumference (smallest measurement between the costal margins and the iliac crests) and hip circumference (at the level of the greater trochanters) were measured with a tape to the nearest $0.5 \mathrm{~cm}$ with the subject standing. Intra-abdominal fat mass was assessed by measuring the abdominal diameter at the level of the iliac crests with a
KEY POINTS
- Indians (South Asians) have more coronary heart disease than Malays and Chinese.

- Indians have more central obesity, but not more general obesity, than Malays and Chinese.

- With regard to "syndrome X", Indians have hyperinsulinaemia, more glucose intolerance, lower mean serum HDL cholesterol, and higher mean plasma PAI-1 but not more hypertension or higher fasting serum triglyceride values.

- Indians have higher mean serum lipoprotein(a) concentrations

ruler and tape to the nearest $0.5 \mathrm{~cm}$ with the subject lying supine.

Blood pressures were taken using the standard mercury sphygmomanometer. The same doctor $(\mathrm{KH})$ did the measuring to remove inter-observer variation, and it was carried out according to the MONICA project protocol ${ }^{14}$ to reduce intra-observer variation. Measurement took place between 09.00 and 11.00 hours to remove diurnal variation. Phases 1 and 5 were recorded and the mean of two readings used for the analyses. All subjects were assessed by the same doctor $(\mathrm{KH})$ who made a diagnosis of hypertension if the person was on current antihypertensive medication or had systolic blood pressure $\geqslant 160 \mathrm{mmHg}$ and/or diastolic blood pressure $\geqslant 95 \mathrm{mmHg}$.

Venous blood samples were taken with the subject in a sitting position. Venoject vacuum containers with minimal venous stasis were used. Venepuncture took place between 10.00 and 12.00 hours to remove diurnal variation, and after at least 10 minutes rest. All measurements were made in the Department of Laboratory Medicine, National University Hospital. The first two specimens were collected in plain vacutainers and serum was analysed within 1 hour. Lipids were measured enzymatically on an autoanalyser (Ektachem, Kodak) - total cholesterol and triglyceride directly and HDL cholesterol after precipitation, with LDL cholesterol calculated from the Friedewald formula. Measurements of apolipoproteins (Apo) B and A1 were by immunonephelometry on the Beckman Array and determination of $L p(a)$ was by enzyme immunoassay using Terumo kits. Insulin was measured by microparticle enzyme immunoassay using Abbott IMX. Fasting serum insulin is used as an index of insulin resistance as the hyperinsulinaemic euglycaemic clamp and the insulin suppression test are not suitable for epidemiological surveys.

The third and fourth specimens of blood were collected in citrated vacutainers $(4.5 \mathrm{ml}$ of blood and $0.5 \mathrm{ml}$ of $3.2 \%$ trisodium citrate). The blood was immediately double spun at $3000 \mathrm{~g}$ for 15 minutes each time and platelet free plasma was removed. Fibrinogen and factor VIIc were measured within two hours, the former by the turbidimetric method on the 
Table 1 Pearson partial correlation coefficients adjusted for age (significance level, p) between serum insulin and other factors for fasting subjects in relation to gender and ethnic group in people aged 30 to 69 years*

\begin{tabular}{|c|c|c|c|c|c|c|}
\hline \multirow[t]{2}{*}{ Factor } & \multicolumn{3}{|l|}{ Men } & \multicolumn{3}{|l|}{ Women } \\
\hline & $\begin{array}{l}\text { Indians } \\
(n=137)\end{array}$ & $\begin{array}{l}\text { Malays } \\
(n=122)\end{array}$ & $\begin{array}{l}\text { Chinese } \\
(n=142)\end{array}$ & $\begin{array}{l}\text { Indians } \\
(n=147)\end{array}$ & $\begin{array}{l}\text { Malays } \\
(n=118)\end{array}$ & $\begin{array}{l}\text { Chinese } \\
(n=152)\end{array}$ \\
\hline Body mass index & $0.53(<0.01)$ & $0.61(<0.01)$ & $0.51(<0.01)$ & $0.27(<0.01)$ & $0.53(<0.1)$ & $0.30(<0.01)$ \\
\hline Waist-hip ratio & $0.33(<0.01)$ & $0.32(<0.01)$ & $0.30(<0.01)$ & $0.23(<0.01)$ & $0.38(<0.01)$ & $0.31(<0.01)$ \\
\hline Abdominal diameter & $0.44(<0.01)$ & $0.64(<0.01)$ & $0.48(<0.01)$ & $0.40(<0.01)$ & $0.60(<0.01)$ & $0.40(<0.01)$ \\
\hline Systolic blood pressure & $0.14(0.09)$ & $0.23(0.01)$ & $0.31(<0.01)$ & $0.15(0.06)$ & $0.20(0.02)$ & $0.24(<0.01)$ \\
\hline Diastolic blood pressure & $0.22(<0.01)$ & $0.32(<0.01)$ & $0.33(<0.01)$ & $0.24(<0.01)$ & $0.23(0.01)$ & $0.23(<0.01)$ \\
\hline Serum LDL cholesterol & $-0.03(0.73)$ & $-0.05(0.60)$ & $-0.06(0.46)$ & $-0.02(0.79)$ & $0.04(0.67)$ & $-0.02(0.76)$ \\
\hline Serum HDL cholesterol & $-0.14(0.10)$ & $-0.10(0.25)$ & $-0.29(<0.01)$ & $-0.18(0.02)$ & $-0.23(0.01)$ & $-0.23(<0.01)$ \\
\hline Serum triglyceride & $0.21(0.01)$ & $0.12(0.19)$ & $0.25(<0.01)$ & $0.31(<0.01)$ & $0.60(<0.01)$ & $0.45(<0.01)$ \\
\hline Serum apolipoprotein B & $0.12(0.15)$ & $0.12(0.17)$ & $0.15(0.08)$ & $0.13(0.11)$ & $0.35(<0.01)$ & $0.17(0.04)$ \\
\hline Serum apolipoprotein A1 & $-0.07(0.42)$ & $-0.17(0.06)$ & $-0.22(<0.01)$ & $0.04(0.60)$ & $-0.07(0.48)$ & $-0.05(0.52)$ \\
\hline Serum lipoprotein(a) & $-0.19(0.02)$ & $-0.25(<0.01)$ & $-0.06(0.45)$ & $-0.14(0.07)$ & $-0.08(0.36)$ & $-0.07(0.37)$ \\
\hline Plasma PAI-1 & $0.21(0.01)$ & $0.42(<0.01)$ & $0.20(0.01)$ & $0.42(<0.01)$ & $0.48(<0.01)$ & $0.32(<0.01)$ \\
\hline Plasma tPA antigen & $0.27(<0.01)$ & $0.47(<0.01)$ & $0.34(<0.01)$ & $0.39(<0.01)$ & $0.50(<0.01)$ & $0.43(<0.01)$ \\
\hline Plasma fibrinogen & $0.12(0.17)$ & $0.16(0.08)$ & $0.18(0.03)$ & $0.06(0.47)$ & $0.26(<0.01)$ & $0.15(0.06)$ \\
\hline Plasma factor VIIc & $-0.01(0.88)$ & $0.21(0.01)$ & $0.01(0.91)$ & $0.02(0.80)$ & $0.14(0.12)$ & $0.03(0.68)$ \\
\hline Plasma prothrombin fragment $1+2$ & $-0.12(0.16)$ & $-0.13(0.14)$ & $-0.19(0.02)$ & $-0.23(<0.01)$ & $0.15(0.10)$ & $-0.05(0.54)$ \\
\hline
\end{tabular}

$\mathrm{LDL}=$ low density lipoprotein, $\mathrm{HDL}=$ high density lipoprotein, PAI-1 = plasminogen activator inhibitor 1 , tPA = tissue plasminogen activator.

* Excludes diabetics on treatment.

Dupont aca analyser and the latter by the one stage clotting assay on the Cobas fibrometer (Roche Diagnostica). Alliquots of plasma were kept frozen at $-70^{\circ} \mathrm{C}$ for subsequent measurement in batches. The prothrombin fragment (F) $1+2$ (which indicates thrombin formation and therefore activation of the coagulation system) was determined using ELISA kits from Behring (Enzygnost F1 + 2) and PAI-1 and tPA were measured by ELISA kits from Diagnostica Stago, France.

The fifth specimen was $2 \mathrm{ml}$ of blood collected in a fluoride oxalate vacutainer with plasma glucose measured within 1 hour by specific enzyme assay on the Kodak Analyser. Subjects with a glucose concentration $\geqslant 5.5 \mathrm{mmol} / 1$ who were not currently on medication for diabetes, subsequently had an oral glucose tolerance test (after at least 10 hours' fasting) of $75 \mathrm{~g}$ of dextrose in $296 \mathrm{ml}$ of carbonated orange (Trutol 75, Custom Laboratories Inc, USA). They then had measurements of plasma glucose at fasting and 2 hours after the oral glucose. They were classified according to the results of their 2-hour glucose concentration as having diabetes $(\geqslant 11.1 \mathrm{mmol} / \mathrm{l})$, impaired glucose tolerance $(7.8$ to $<11.1 \mathrm{mmol} /$ $1)$, or normal $(<7.8 \mathrm{mmol} / \mathrm{l}) .{ }^{15}$ Those with a fasting plasma glucose concentration $<5.5 \mathrm{mmol} / 1$ are very unlikely to have diabetes. ${ }^{16}$ Subjects currently taking medication for diabetes were also classified as diabetic. Of the diabetics, only two (both Chinese women less than 40 years) were insulin dependent and so the analysis is of non-insulin dependent diabetes mellitus (NIDDM). A classification of glucose intolerance was made with either diabetes or impaired glucose tolerance.

\section{ANALYSIS}

The mean ages were very similar in relation to gender and ethnic group These were as follows: Indians, men 46.8 and women 45.8 years; Malays, men 46.7 and women 46.1 years; and Chinese, men 46.9 and women 46.7 years. Nevertheless, age adjustment was performed. Pearson product moment partial correlation coefficients (after adjusting for age) between serum insulin and other factors were calculated using SPSS software. Age adjustment for means was by analysis of covariance using the $G L M$ procedure of $S A S$ and for prevalences by direct standardisation to the total population of the sample with significance testing by the $\mathrm{Z}$ test. All significance testing was two tailed. Only subjects who had fasted at least 10 hours (96.8\% of the total) were used in the analyses of triglyceride and insulin, and also of PAI-1 and tPA (as lipaemia can affect measurement of the fibrinolytic system). For insulin measurements, diabetics on treatment were excluded.

\section{Results}

CORRELATIONS BETWEEN FASTING SERUM

INSULIN AND OTHER FACTORS (TABLE 1)

For all six gender-ethnic groups, the fasting insulin value was strongly and directly correlated with body mass index (BMI), waist-hip ratio (WHR), and abdominal diameter, least strongly with WHR (see table 1). There were direct correlations with systolic and diastolic blood pressures. There were no correlations with LDL cholesterol but inverse ones with HDL cholesterol and direct ones with fasting triglyceride values. There were no important correlations with Apo B or Apo A1, and while all correlations with $\operatorname{Lp}(a)$ were inverse some of the coefficients were small and statistically insignificant. Fasting insulin was strongly and directly correlated with PAI-1 and tPA. There was a direct and statistically significant correlation with fibrinogen in some but not all groups and no evidence at all of correlations with factor VIIc and prothrombin $\mathrm{F} 1+2$.

MEAN LEVELS AND PREVALENCES OF FACTORS Mean BMI was higher in women than men for Indians and Malays (tables 2 and 3 ) but the same for Chinese. For both genders BMI was highest in Malays, then Indians and then Chinese. Mean WHRs (higher in men than women) were highest in Indians for both genders; in men Malays had a slightly higher ratio than Chinese, while in women there was no 
Table 2 Means and prevalences (95\% confidence intervals) of factors for Indians (I), Malays (M) and Chinese (C), men age adjusted* for age group 30 to 69 years

\begin{tabular}{|c|c|c|c|c|c|c|}
\hline \multirow[t]{2}{*}{ Factor } & \multirow{2}{*}{$\begin{array}{l}\text { Indians } \\
(n=170)\end{array}$} & \multirow{2}{*}{$\begin{array}{l}\text { Malays } \\
(n=147)\end{array}$} & \multirow{2}{*}{$\begin{array}{l}\text { Chinese } \\
(n=161)\end{array}$} & \multicolumn{3}{|c|}{ Significance level, $p$} \\
\hline & & & & $I v M$ & $I v C$ & $M v C$ \\
\hline Body mass index $\left(\mathrm{kg} / \mathrm{m}^{2}\right)$ & $24.2(23.6,24.8)$ & $25.7(25.1,26.3)$ & $23.3(22.7,23.9)$ & $<0.01$ & 0.03 & $<0.01$ \\
\hline Waist-hip ratio & $0.93(0.92,0.94)$ & $0.91(0.90,0.92)$ & $0.90(0.89,0.91)$ & 0.05 & $<0.01$ & 0.10 \\
\hline Abdominal diameter $(\mathrm{cm})$ & $22.7(22.3,23.1)$ & $22.3(21.9,22.8)$ & $21.0(20.6,21.4)$ & 0.18 & $<0.01$ & $<0.01$ \\
\hline Fasting serum insulin (mU/1)t & $8.6(7.7,9.5)$ & $7.0(6.0,8.0)$ & $6.5(5.6,7.4)$ & 0.02 & $<0.01$ & 0.45 \\
\hline Glucose intolerance $(\%)$ & $27.8(19.9,35.8)$ & $19.0(11.8,26.1)$ & $11.1(6.1,16.1)$ & 0.04 & $<0.01$ & 0.03 \\
\hline Systolic blood pressure $(\mathrm{mmHg})$ & $130(127,133)$ & $133(130,136)$ & $129(126,132)$ & 0.32 & 0.35 & 0.06 \\
\hline Diastolic blood pressure (mmHg) & $82(80,84)$ & $84(82,86)$ & $82(80,84)$ & 0.32 & 0.55 & 0.12 \\
\hline Hypertension (\%) & $20.7(13.9,27.6)$ & $20.2(12.8,27.5)$ & $18.0(11.5,24.4)$ & 0.89 & 0.49 & 0.60 \\
\hline Serum LDL cholesterol $(\mathrm{mmol} / \mathrm{l})$ & $4.0(3.9,4.1)$ & $4.1(4.0,4.2)$ & $3.9(3.8,4.0)$ & 0.56 & 0.17 & 0.06 \\
\hline Serum HDL cholesterol $(\mathrm{mmol} / \mathrm{l})$ & $0.73(0.70,0.76)$ & $0.78(0.75,0.81)$ & $0.88(0.85,0.91)$ & 0.06 & $<0.01$ & $<0.01$ \\
\hline Fasting serum triglyceride $(\mathrm{mmol} / \mathrm{l})$ & $1.8(1.7,1.9)$ & $1.8(1.7,1.9)$ & $1.6(1.5,1.7)$ & 0.75 & 0.06 & 0.14 \\
\hline Serum apolipoprotein $\mathbf{B}(\mathrm{mg} / \mathrm{dl})$ & $128(123,133)$ & $124(118,130)$ & $120(114,126)$ & 0.32 & 0.03 & 0.30 \\
\hline Serum apolipoprotein $\mathrm{Al}(\mathrm{mg} / \mathrm{dl})$ & $127(124,130)$ & $132(129,135)$ & $140(137,143)$ & 0.03 & $<0.01$ & $<0.01$ \\
\hline Serum lipoprotein(a) (mg/dl) & $18.1(15.6,20.6)$ & $14.8(12.1,17.5)$ & $12.5(9.8,15.2)$ & 0.09 & $<0.01$ & 0.25 \\
\hline Plasma PAI-1 (ng/ml) & $26.7(24.0,29.4)$ & $24.3(21.4,27.2)$ & $21.8(18.9,24.7)$ & 0.25 & 0.01 & 0.25 \\
\hline Plasma tPA antigen $(\mathrm{ng} / \mathrm{ml})$ & $10.3(10.0,10.6)$ & $9.1(8.6,9.6)$ & $8.4(7.9,8.9)$ & $<0.01$ & $<0.01$ & 0.09 \\
\hline Plasma fibrinogen $(\mathrm{g} / \mathrm{l})$ & $2.7(2.6,2.8)$ & $2.9(2.8,3.0)$ & $2.6(2.5,2.7)$ & 0.03 & 0.32 & $<0.01$ \\
\hline Plasma factor VIIc (\%) & $126(120,132)$ & $132(125,139)$ & $128(122,134)$ & 0.23 & 0.68 & 0.43 \\
\hline Plasma prothrombin $\mathrm{F} 1+2(\mathrm{nmol} / \mathrm{l})$ & $1.5(1.4,1.6)$ & $1.6(1.5,1.7)$ & $1.4(1.3,1.5)$ & 0.30 & 0.60 & 0.13 \\
\hline
\end{tabular}

$\mathrm{PAI}=$ plasminogen activator inhibitor, $\mathrm{tPA}=$ tissue plasminogen activator.

* By analysis of covariance for means and direct standardisation for prevalences.

† Excludes diabetics on treatment.

Table 3 Means and prevalences (95\% confidence intervals) of factors for Indians (I), Malays (M) and Chinese (C), women age adjusted* for age group 30 to 69 years

\begin{tabular}{|c|c|c|c|c|c|c|}
\hline \multirow[t]{2}{*}{ Factor } & \multirow{2}{*}{$\begin{array}{l}\text { Indians } \\
(n=172)\end{array}$} & \multirow{2}{*}{$\begin{array}{l}\text { Malays } \\
(n=142)\end{array}$} & \multirow{2}{*}{$\begin{array}{l}\text { Chinese } \\
(n=169)\end{array}$} & \multicolumn{3}{|c|}{ Significance level, $p$} \\
\hline & & & & $I v M$ & $I v C$ & $M v C$ \\
\hline Body mass index $\left(\mathrm{kg} / \mathrm{m}^{2}\right)$ & $26.2(25.6,26.8)$ & $27.3(26.7,27.9)$ & $23.6(23.0,24.2)$ & 0.01 & $<0.01$ & $<0.01$ \\
\hline Waist-hip ratio & $0.84(0.83,0.85)$ & $0.82(0.81,0.83)$ & $0.82(0.81,0.83)$ & $<0.01$ & $<0.01$ & 0.98 \\
\hline Abdominal diameter $(\mathrm{cm})$ & $22.4(22.0,22.8)$ & $22.2(21.7,22.7)$ & $20.2(19.8,20.6)$ & 0.56 & $<0.01$ & $<0.01$ \\
\hline Fasting serum insulin (mU/l) & $9.1(8.2,10.0)$ & $7.7(6.7,8.7)$ & $7.0(6.1,7.9)$ & 0.05 & $<0.01$ & 0.29 \\
\hline Glucose intolerance $(\%)$ & $20.3(13.5,27.1)$ & $21.0(13.4,28.7)$ & $9.7(5.1,14.3)$ & 0.86 & $<0.01$ & $<0.01$ \\
\hline Systolic blood pressure (mmHg) & $130(127,133)$ & $135(132,138)$ & $130(127,133)$ & 0.01 & 0.72 & 0.02 \\
\hline Diastolic blood pressure $(\mathrm{mmHg})$ & $79(77,81)$ & $82(80,84)$ & $80(78,82)$ & 0.01 & 0.27 & 0.14 \\
\hline Hypertension (\%) & $19.6(12.9,26.3)$ & $22.0(14.1,29.9)$ & $19.8(13.2,26.4)$ & 0.58 & 0.95 & 0.62 \\
\hline Serum LDL cholesterol $(\mathrm{mmol} / \mathrm{l})$ & $4.0(3.9,4.1)$ & $4.1(4.0,4.2)$ & $3.9(3.8,4.0)$ & 0.52 & 0.29 & 0.10 \\
\hline Serum HDL cholesterol (mmol/1) & $0.88(0.85,0.91)$ & $0.96(0.93,0.99)$ & $1.03(1.00,1.06)$ & $<0.01$ & $<0.01$ & $<0.01$ \\
\hline Fasting serum triglyceride $(\mathrm{mmol} / \mathrm{l})$ & $1.5(1.4,1.6)$ & $1.6(1.5,1.7)$ & $1.4(1.3,1.5)$ & 0.33 & 0.58 & 0.13 \\
\hline Serum apolipoprotein $\mathbf{B}(\mathrm{mg} / \mathrm{dl})$ & $120(115,125)$ & $120(114,126)$ & $114(109,119)$ & 0.96 & 0.11 & 0.15 \\
\hline Serum apolipoprotein $\mathrm{Al}(\mathrm{mg} / \mathrm{dl})$ & $138(135,141)$ & $145(142,148)$ & $155(152,158)$ & $<0.01$ & $<0.01$ & $<0.01$ \\
\hline Serum lipoprotein $(\mathrm{a})(\mathrm{mg} / \mathrm{dl})$ & $22.7(20.2,25.2)$ & $17.4(14.7,20.1)$ & $18.5(16.0,21.0)$ & $<0.01$ & 0.03 & 0.60 \\
\hline Plasma PAI-1 (ng/ml) & $29.5(26.8,32.2)$ & $22.7(19.6,25.8)$ & $22.5(19.8,25.2)$ & $<0.01$ & $<0.01$ & 0.92 \\
\hline Plasma tPA antigen $(\mathrm{ng} / \mathrm{ml})$ & $9.2(8.9,9.5)$ & $7.8(7.3,8.3)$ & $6.8(6.5,7.1)$ & $<0.01$ & $<0.01$ & 0.02 \\
\hline Plasma fibrinogen $(\mathrm{g} / \mathrm{l})$ & $3.3(3.2,3.4)$ & $3.1(3.0,3.2)$ & $3.0(2.9,3.1)$ & $<0.01$ & $<0.01$ & 0.06 \\
\hline Plasma factor VIIc (\%) & $139(133,145)$ & $148(141,155)$ & $136(130,142)$ & 0.08 & 0.52 & 0.02 \\
\hline Plasma prothrombin $\mathrm{F} 1+2(\mathrm{nmol} / \mathrm{l})$ & $1.7(1.6,1.8)$ & $1.9(1.8,2.0)$ & $1.6(1.5,1.7)$ & 0.20 & 0.54 & 0.06 \\
\hline
\end{tabular}

$\mathrm{PAI}=$ plasminogen activator inhibitor, $\mathrm{tPA}=$ tissue plasminogen activator.

* By analysis of covariance for means and direct standardisation for prevalences.

$\uparrow$ Excludes diabetics on treatment.

difference. Abdominal diameter (similar in both genders for Indians and Malays but higher in men than women for Chinese) was higher in Indians and Malays than Chinese for both genders.

Fasting insulin values were higher in women than in men and for both genders were highest in Indians; Malays had higher levels than Chinese but the differences were not statistically significant. The prevalence of glucose intolerance was highest in Indians, then Malays, and then Chinese for men, while for women it was virtually the same in Indians and Malays, with both having higher prevalences than Chinese. Blood pressure levels in relation to ethnic group were similar for men and slightly higher in Malays for women, with no ethnic differences in prevalences of hypertension for both genders.

Mean LDL cholesterol concentrations (similar in the two genders) were similar in the three ethnic groups for both genders. However, HDL cholesterol values (higher in women than men) were highest in Chinese, then in Malays, and then in Indians for both genders. Fasting triglyceride concentrations (higher in men than women) were slightly higher in Indians and Malays than in Chinese but the differences were not statistically significant. Apo $B$ values (similar in both genders) were lower in Chinese than in Indians and Malays but the differences were only statistically significant in men. Apo Al values (higher in women than men) were highest in Chinese, then in Malays, and then in Indians for both genders. As in studies elsewhere, all six distributions of $\operatorname{Lp}(a)$ were skewed to the right. Serum $\operatorname{Lp}(a)$ was higher in women than men, and for both genders concentrations were higher in Indians than $\mathrm{Ma}-$ lays and Chinese, which showed no differences.

There was little gender difference in PAI-1 levels. These were higher in Indians than in Malays and Chinese (though for men the difference with Malays was not statistically significant) With regard to tPA levels (higher in men than women), these were highest in Indians, then Malays and then Chinese, for both genders. Fibrinogen values were higher in women than men, and while there were some statistically significant ethnic differences there was no consistency, with concentrations highest 
in Malays for men and in Indians for women. Both factor VIIc and prothrombin F1 +2 levels were higher in women than men, and the only ethnic differences were for women, with Malays having slightly higher concentrations.

\section{Discussion}

Correlations between fasting serum insulin and other risk factors are consistent across the six groups, showing that syndrome $\mathrm{X}$ operates similarly in both genders and in the three ethnic groups. Fasting insulin is strongly correlated with obesity, more strongly for BMI than WHR as has been found elsewhere. ${ }^{617}$ The reason for this is not clear. However insulin is as strongly correlated with abdominal diameter (used as a measure of abdominal or visceral fat) as BMI.

Those cardiovascular risk factors that are strongly and consistently correlated with fasting insulin (blood pressures, HDL cholesterol, fasting triglyceride, PAI-1, and tPA) are identified as components of syndrome $\mathrm{X}$, while those factors that are not correlated with fasting insulin (LDL cholesterol, Apo B, Apo A1, Lp(a), fibrinogen, factor VIIc, and prothrombin $F 1+2)$ are not identified as components of syndrome $\mathrm{X}$. Syndrome $\mathrm{X}$ increases the risk of atherosclerosis and thrombosis, the latter from reduced fibrinolytic activity due to increased PAI-1.

In Singapore, WHRs in male Indians are lower than values in London, ${ }^{6}$ but the same as those in Bradford. ${ }^{7}$ For women the values are the same as in London. ${ }^{6}$ In both genders Malays tend to develop generalised obesity (measured by $\mathrm{BMI}$ ), while Indians preferentially develop central obesity (measured by WHR). Furthermore, Indians have higher fasting insulin levels. Hence, Indians are more prone than Malays and Chinese to develop the central obesity-insulin resistance syndrome. While this syndrome can have genetic and environmental causes, ${ }^{18}$ there are no apparent environmental differences other than diet among the ethnic groups in Singapore. It has been postulated that it is more pronounced in Indians because of low physical activity and high energy intake in a population adapted to survival under conditions of unreliable food supply and physically demanding work. ${ }^{6}$ Against this explanation for the findings among Indians in Singapore is the fact that the Chinese have also come from such a background and Malays have higher general obesity levels than Indians. There is no evidence in Singapore that Indians have lower levels of physical activity than Malays or Chinese. ${ }^{19}$

Whether hyperinsulinaemia in Indians can itself lead to increased CHD is not clear. It has been argued that the relation between hyperinsulinaemia and CHD is due to related risk factors, ${ }^{20}$ but a recent study found hyperinsulinaemia to be an independent risk factor. ${ }^{21}$

Ethnic differences in glucose intolerance are the same as in the previous survey. ${ }^{13}$ The high prevalence of glucose intolerance in Malay women no doubt results from their high levels of obesity. More glucose intolerance will con- tribute to Indians' higher risk of CHD and to the higher risk of Malays compared with Chinese.

No important ethnic differences in blood pressures and hypertension were found, as in the previous survey ${ }^{13}$ and another survey in Singapore. ${ }^{22}$ The finding that Indians do not have higher blood pressures is further indicated by the fact that they do not have higher mortality than the other two ethnic groups from cerebrovascular disease, ${ }^{12}$ for which hypertension is the main risk factor. While studies vary on this, it has been pointed out that while Indians have relatively high CHD mortality they do not usually have a higher prevalence of hypertension than other ethnic groups. ${ }^{23}$ The relationship between insulin resistance and hypertension is controversial ${ }^{24}$ with evidence that it may differ in relation to ethnic group. ${ }^{25}$

No ethnic differences have been found for LDL cholesterol (as in the previous survey, ${ }^{13}$ ), while, for men, the slightly higher levels of Apo $B$ in Indians and Malays than in Chinese have also been reported previously. ${ }^{26}$ Ethnic differences in HDL cholesterol are the same as in the previous survey, ${ }^{13}$ and, in agreement, similar ethnic differences have been found for Apo A1. Indians' lower HDL cholesterol cannot be explained by a lower alcohol intake, ${ }^{27}$ or more cigarette smoking. ${ }^{13}$ However, the differences are not great and it should be noted that all three of these Asian groups have lower HDL cholesterol levels than whites, which has been pointed out previously. ${ }^{28}$ Small and statistically insignificant differences have been found for fasting triglyceride, again as in the previous survey. ${ }^{13}$ What is not clear is why Indians do not have higher fasting triglyceride concentrations. However, compared with Europeans, Indians had higher fasting triglyceride in one London study, ${ }^{6}$ levels that were only slightly higher in Bradford, ${ }^{7}$ and levels that were lower in another survey in London, ${ }^{23}$ despite lower levels of HDL cholesterol in Indians in all three surveys.

The finding of higher $\mathrm{Lp}(\mathrm{a})$ levels in Indians is consistent with findings elsewhere. ${ }^{5}$ At least $70 \%$ of the variation in $\mathrm{Lp}(\mathrm{a})$ among populations is considered genetic, ${ }^{29}$ suggesting the reason for higher levels in Indians is at least partly genetic. A study in Singapore found evidence that the distributions of Apo(a) phenotypes (determined by the genotypes) would give higher $L p(a)$ levels in Indians than in Malays and Chinese but also that the Apo(a) type-specific $\mathrm{Lp}(\mathrm{a})$ levels were higher in Indians than in Chinese and Malays suggesting that other unknown factors besides the Apo(a) electromorphs account for the differences in $\mathrm{Lp}(\mathrm{a})$ levels. ${ }^{30}$ The small study size, however, precludes definite conclusions. ${ }^{30}$ Whatever the reason, higher $\mathrm{Lp}(\mathrm{a})$ is a contributor to Indians' higher rates of CHD through an increased risk of atherosclerosis ${ }^{10}$ and thrombosis, ${ }^{11}$ and is probably a major determinant of $\mathrm{CHD}$ in young Indians.

Indians have higher PAI-1 levels than the other two ethnic groups, though in men the difference with Malays is not statistically significant. However, the fact that Indians do have higher PAI-1 levels is further shown by their 
higher tPA levels, which show highly significant differences for all groups. Assays of tPA with immunochemical methods (as in this study) measure active and inactive tPA. The latter is much the larger fraction and is composed of complexes with inhibitors, particularly PAI-1, so that the tPA antigen concentration largely reflects the PAI-1 concentration and an increase in PAI-1 leads to an increase in tPA. ${ }^{31}$ Furthermore, there is evidence that high PAI-1 and TPA antigen levels increase the risk of CHD. ${ }^{31}$ Hence higher levels of PAI-1 and tPA are part of the explanation for Indians' higher risk of CHD. A relationship has been found between PAI-1 and insulin resistance, ${ }^{17}{ }^{32}$ but whether higher levels of PAI-1 in Indians can be completely explained by hyperinsulinaemia or whether there are also other causes such as genetic ones is not clear. Higher levels of $\mathrm{Lp}(\mathrm{a})$ in Indians may help to increase PAI-1 and will accentuate its antifibrinolytic effect. ${ }^{11}$ Similar levels of fibrinogen, factor VIIc, and prothrombin $F 1+2$ indicate no ethnic differences in coagulation.

In conclusion, this study in Singapore has shown that Indians are more prone than two other Asian ethnic groups (Malays and Chinese) to develop central obesity (the reason for which is not clear) with insulin resistance, hyperinsulinaemia, and glucose intolerance. This leads to some but not all of the features of syndrome X, with lower HDL cholesterol and higher PAI-1 levels. In addition, Indians have higher $\mathrm{Lp}(\mathrm{a})$ levels. Whether or not all this can fully explain the much greater susceptibility of Indians to CHD is not clear and other possible reasons have been investigated in the National University of Singapore heart study.

Funding: The National University of Singapore and National Medical Research Council.

Conflicts of interest: none.

1 McKeigue PM. Coronary heart disease in Indians, $\mathrm{Pa}$ kistanis, and Bangladeshis: aetiology and possibilities fo prevention. Br Heart $\mathcal{F}$ 1992;67:341-42.

2 Gupta S, de Belder A, Hughes LO. Avoiding premature coronary deaths in Asians in Britain. BMF 1995;311: $1035-36$.

3 Stern MP, Haffner SM. Body fat distribution and hyperinsulinaemia as risk factors for diabetes and cardiovascular disease. Arteriosclerosis 1986;6:123-30.

4 Reaven GM. Role of insulin resistance in human disease. Diabetes 1988;37:1595-607.

5 Enas EA, Mehta J. Malignant coronary artery disease in young Asian Indians: Thoughts on pathogenesis, preyoung Asian Indians: Thoughts on pathogenesis,

6 McKeigue PM, Shah B, Marmot MG. Relation of central obesity and insulin resistance with high diabetes prevalence and cardiovascular risk in South Asians. Lancet 1991;337: 382-86

7 Knight TM, Smith Z, Whittles A, et al. Insulin resistance, diabetes, and risk markers for ischaemic heart disease in Asian men and non-Asian men in Bradford. Br Heart $f$ 1992;67:343-50.

8 Reaven GM. Pathophysiology of insulin resistance in human disease. Physiol Rev 1995;75:473-86.

9 Nordoy A. Haemostatic factors in coronary heart disease. f Intern Med 1993;233:377-83.

10 Scanu AM, Lawn RM, Berg K. Lipoprotein(a) and atherosclerosis. Ann Intern Med 1991;115:209-18.

11 Hajjar KA, Gavish D, Breslow JL, Hachman RL. Lipoprotein(a) modulation of endothelial cell surface fib rinolysis and its potential role in atherosclerosis. Natur 1989;339:303-5.

12 Hughes K, Lun KC, Yeo PBB. Cardiovascular diseases in Chinese, Malays, and Indians in Singapore. I. Differences in mortality. F Epidemiol Community Health 1990;44:24-28.

13 Hughes K, Yeo PBB, Lun KC, et al. Cardiovascular disease in Chinese, Malays, and Indians in Singapore. II. Differences in risk factor levels. $\mathcal{F}$ Epidemiol Community Health 1990;44:29-35.

14 World Health Organization. Multinational monitoring of trend and determinants in cardiovascular diseases, "Monica Project": Manual of Operations. Geneva: World Health Organization, 1982 .

15 WHO Study Group on Diabetes Mellitus. Diabetes mellitus. WHO Technical Reports Series 1985 no $727: 1-113$

16 WHO Study Group on Diabetes Mellitus. Prevention of diabetes mellitus. WHO Technical Reports Series 1994 no 844:1-100(18)

17 Lindahl B, Asplund K, Eliasson M, Evrin PE. Insulin resistance syndrome and fibrinolytic activity: The norther Sweden MONICA study. Int F Epidemiol 1996;25:291-99.

18 Dhawan J, Bray CI, Warburton R, Ghambhir DS, Morris $\mathrm{J}$. Insulin resistance, high prevalence of diabetes, and cardiovascular risk in immigrant Asians. Genetic or environmental effect? Br Heart $\mathcal{f}$ 1994;72:413-21.

19 Hughes K, Yeo PPB, Lun KC, Thai AC, Wang KW, Cheah JS. Physical activity in Chinese, Malays and Indians in Singapore. Ann Acad Med Singapore 1990;19:326-29.

20 Fontbonne A. Why can high insulin levels indicate a risk for coronary heart disease? Diabetologia 1994;37:953-55.

21 Despres JP, Lamarche B, Mauriege P, et al. Hyperinsulinaemia as an independent risk factor for ischaemic perinsulinaemia as an independent risk factor for

22 Lee HP, Seah CS, Yik TY, et al. An epidemiological survey of blood pressures in Singapore. $\mathcal{F}$ Chronic Dis 1977:30 793-802.

23 Miller GJ, Kotecha S, Wilkinson WH, et al. Dietary and other characteristics relevant for coronary heart disease in men of Indian, West Indian and European descent in London. Atherosclerosis 1988;70:63-72.

24 Williams B. Insulin resistance: the shape of things to come. Lancet 1994;344:521-24.

25 Saad MF, Lillioja S, Nyomba BL, et al. Racial differences in the relation between blood pressure and insulin resistance. New Engl f Med 1991;324:733-39.

26 Saha N. Serum high density lipoprotein cholesterol, apolipoprotein A-1, A-II and B levels in Singapore ethnic groups protein A-1, A-II and B levels in

27 Hughes K, Yeo PPB, Lun KC, Thai AC, Wang KW, Cheah JS. Alcohol consumption in Chinese, Malays and Indian in Singapore. Ann Acad Med Singapore 1990;19:330-32.

28 Hughes K, Yeo PPB, Lun KC, et al. Ischaemic heart disease and its risk factors in Singapore in comparison with othe countries. Ann Acad Med Singapore 1989;18:245-49.

29 Anonymous. Editorial. Lipoprotein(a). Lancet 1991;337 397-98.

30 Sandholzer C, Hallman DM, Saha N, et al. Effects of the apolipoprotein(a) size polymorphism on the lipoprotein(a) concentration in 7 ethnic groups. Hum Genet 1991;86: 607-14.

31 Wiman B. Plasminogen activator inhibitor 1 (PAI-1) in plasma: Its role in thrombotic disease. Thromb Haemost 1995;74:71-76.

32 Juhan Vague I, Thompson SG, Jespersen J. Involvement of the hemostatic system in the insulin resistance syndrome. A study of 1500 patients with angina pectoris. The ECAT A study of 1500 patients with angina pectoris. The ECAT angina pecto
$1865-73$. 